Journal of English Language Teaching and Applied Linguistics

ISSN: 2707-756X

DOI: 10.32996/jeltal

Journal Homepage: www.al-kindipublisher.com/index.php/jeltal

\title{
The Challenges of Homographs among EFL Learners of the College of Foreign Languages
}

\author{
Latifah Hamdan M. Alghamdi \\ Instructor at the English Language Skills Department of King Saud University in Riyadh, Kingdom of Saudi Arabia
}

$\square$ Corresponding Author: Latifah Hamdan M. Alghamdi, E-mail: Alghamdi.l@outlook.sa

\section{ARTICLE INFORMATION}

Received: 04 October 2021

Accepted: 25 October 2021

Published: 10 November 2021

DOI: 10.32996/jeltal.2021.3.12.1

\section{KEYWORDS}

Homograph, Homography, Homonym, Homophone, Lexical ambiguity, Lexicon Errors, MultiMeaning

\section{ABSTRACT}

The purpose of this study was to investigate the erroneous use (misuse) of homographs among EFL learners of the College of Foreign Languages to determine the misuse of homographs among EFL learners, find out the ability of EFL learners to distinguish homographs, and enrich learners with different usage of some words included in the homographs. The sample of the study consisted of 30 participants, 15 each of male and female students, randomly selected from $7^{\text {th }}-8^{\text {th }}$ levels of the College of Foreign Languages in Albaha University, Kingdom of Saudi Arabia. The participants were assigned to (2) different experiments. A homograph definition was given to them at the beginning of the experiments to make sure that they were equivalent and homogenous. Two different tests were undertaken by the students and the results were obtained. The findings revealed a significant deficiency of students in the first experiment in which they were required to give multi-meanings for each homographic word. This led to the conclusion that there is a serious learning problem as seen in the students' competence and performance.

\section{Introduction}

Homographs are words sharing the same spelling and pronunciation but differing in origin and meanings. The concept of mental lexicon refers to how the human mind cannot help but make meanings. The human mind makes up the language to reach the desired meaning. Some researchers tend to use formal concepts of homographs to extract and visualize ambiguous words and lexicon senses and use the results to identify whether the word's ambiguity was still open or was resolved. In order to master lexical development, it is necessary to understand the way L2 learners hypothesize a word's meaning. Naturally, the language processing must deal with homographs' ambiguities, and the different senses attributed to them.

In this study, the researcher had chosen to investigate the misuse of homographs among the undergraduate students of the English language department of Albaha University, Kingdome of Saudi Arabia, and to find out the ability of second language learners to distinguish homographs semantically and lexically.

\subsection{Purpose of the study}

The purpose of the study is twofold

i. To determine the misuse of homographs among EFL learners.

ii. To find out the ability of EFL learners to distinguish homographs.

iii. To enrich learners with different usage of some words included in the homographs.

\subsection{Statement of the problem}

There are different aspects of homographs and associated concepts, which are put together below to arrive at the statement of the problem of this study

Copyright: (C) 2021 the Author(s). This article is an open access article distributed under the terms and conditions of the Creative Commons Attribution (CC-BY) 4.0 license (https://creativecommons.org/licenses/by/4.0/). Published by Al-Kindi Centre for Research and Development, London, United Kingdom. 


\subsubsection{The different meanings of a word mislead learners to make mental lexicon errors}

Some words sound, and are spelled, the same. Therefore, it is easy to be confused or misled by them. Errors might occur in the mental process, especially if the learners are not familiar with these homographs, or not sufficiently trained to use them. Learners with a lack of awareness of lexical items (such as homonyms, homophone, or homograph), usually tend to make erroneous sentences that make no sense.

\subsubsection{Recognizing the importance of homographs in learning the English language}

Sentence composition is a strong factor to master a language; equally, the meaning also must be correctly comprehendible. Lexical items give meaning to a language. If a learner is not sufficiently conversant with them, then some meanings of related words may be used that may be irrelevant to the required or intended meaning. For example, a learner with a lack of $L 2$ mental lexicon may think that certain words give certain meanings only, regardless of the various usages of these words. A new word may be phonologically familiar to the learners and associated with a referent as in the case of polysemy. Some L2 learners could distinguish a word with one meaning, overlooking the other meanings that the same word may contain, (Leslie, 1994).

In the case of a homograph, the meaning of the word might confuse the learners, though the word itself could be familiar and associated with a referent. In order to explain how $L 2$ learners access multiple meanings for a word, it is necessary to understand how, and under what circumstances, a new meaning for homographs is acquired. To be more specific, L2 learners must understand how the lexical theories of acquisition account for the homographic meanings.

\subsection{3 lexical ambiguity}

One of the factors that lead to the wrong use of homography is lexical ambiguity. Learners aren't familiar with these kinds of homographic words unless they have been trained in this concept. Only a well-trained mind in lexical items, besides good training in grammar and spelling, can compose sentences correctly. Besides that, second language teachers also must be sufficiently trained lexically in order to teach these kinds of lexical concepts.

\subsubsection{Syntactic and Semantic lexical ambiguity}

The ambiguity of language occurs at many levels of linguistics communication, starting from the individual letter perception or sounds, and ending in discourse processing. There is evidence in the literature that context affects lexical processing in general (Leslie, 1994).

Generally, lexical ambiguity occurs when an utterance has multi-meanings because it contains a homograph. The crucial question arises as to how to make the correct meaning when the word with the same spelling is associated with multiple meanings. In this situation, normally the context helps to clear the ambiguity of the word. In particular, reading helps to access particular ideas, meaning, or thoughts from the perceptual analysis of ambiguous sets of words.

Lexical ambiguity is of two types: (a) syntactic, lexical ambiguity that refers to category ambiguity, for example; noun vs. verb. (b) semantic lexical ambiguity that simply refers to words (polysemy, homonym). Hirst (1987) pointed out that polysemy often blends into metaphor. However, semantic and syntactic ambiguity is perpendicular, since a single word can have related and unrelated meanings in different categories.

Based on the various aspects described above, the problem statement can be listed as follows:

i. There possibly are some potential problematic effects of the misuse of homographs.

ii. Can L2 learners really distinguish words semantically, and syntactically

iii. Is there a need to enrich learners with different usage of some homographic words?

\subsection{The objectives of this study}

The study had three main objectives

a. With respect to words, the study looked to clarify the nature of the representation of homographs in the bilingual mental lexicon, by including them in two versions of words that showed their lexical uses.

b. To identify the different meanings of the word classes of some homographs included in this study.

c. To determine the ability of second language learners to use homographs correctly.

\subsection{Significance of the study}

To satisfy L2 learners' needs by:

a. Enabling learners to use homographs correctly in sentences.

b. Raising the level of lexical awareness and comprehension in order to understand homograph meanings in a context. 


\subsection{Research Question}

The tests of this study were constructed in order to obtain information on the following question:

Can the learners recognize the different meanings and the word classes of a homograph? In short, do they understand the contextual meaning of the same?

\subsection{Research Limitation}

This study was carried out in just one Institute and this will hinder generalizing its findings. But it is a pointer to what is the reality, which can be uncovered by more comprehensive studies. The focus of the study is also limited to one type of error - the wrong use of a multi-meaning word. But this understanding can reinforce larger studies of various types of errors

\section{Literature review}

\subsection{Introduction}

Grauberg (1971) noted that the language of foreign learners contains many different types of errors. He suggests that lexical errors most frequently occurred while understanding and writing unfamiliar words. Carter (1998: 185) suggests that "mistakes in lexical selection may be less generously tolerated outside classrooms than mistakes in syntax". This is probably because lexical selection consists mainly of content words that convey the intended message. Hemchua (2006) suggests that "When inappropriate lexical choices are made (lexical errors), this can lead directly to a misunderstanding of the message, or at least increase the burden of interpreting the text."

Despite the frequency of lexical errors by EFL learners, it remains under-researched. Writings of L2 students show the importance of vocabulary composition in second language learning which is widely accepted. But there has been relatively little research on the lexical errors the learners produce when they learn their second language. This situation led to the current study, and its objectives as spelled out in Sec 1.4 above. A caveat is the author has focused on only one type of these errors - the wrong use of a multi-meaning word, in order to investigate the causes of these errors.

\section{2 Related studies}

Kurcz (2000) describes a mental lexicon (or mental dictionary) as an organization of morphemes that provide an intuitive knowledge of somaticized, syntactic, phonology, and spelled language. It can be studied quantitatively using 'word frequency'. Poor mental lexicon could be due to memory deficits and long-term memory losses (M. Bogdanowicz, 2004a; Lundberg and Hoien, 2001; Swanson \& Sáez, 2003). This affects the learning of second language students.

Often, second language learners show confusion in choosing the suitable meaning of a word that has multiple meanings. This is the challenge posed by homographs - two words that are spelled exactly the same way but have different meanings and sometimes different word classes. One of the lexical problems overwhelmingly faced by second language learners is the confusion, and thereby the incorrect use or misuse, of homographs. (Misuse of homographs is understood as incorrect or erroneous use and not abuse). According to Neill \& Kelin (1989), a homograph is a particularly attractive stimulus type to use because anthographs are more restricted, with only the meaning being vague, but no other challenge Usually, it eradicates the influences of uncontrolled lexical variables

An analysis of lexical errors in the English homographs of second language learners was made by Hemchua (2006). It confirmed that when inappropriate lexical choices are made (lexical errors), this can lead directly to a misunderstanding of the message or at least increase the burden of interpreting the text. Swinney (1979) contends that for many models of lexical misuses, resolution of the different meanings of homographs is crucial. Based on what linguists have mentioned, several homograph association norms were published about lexical errors that misled learners in identifying word meanings.

Several authors have addressed the nature of homograph misuse. Simpson (1988) claims that misuse of homographs occurred widely with L2 learners of any language. Some researchers, like Kitsch \& Morass, were interested in the ambiguity resolution when the homograph was presented in isolation, without the context. The context somewhere guides the receiver to comprehend the meaning clearly, but the isolated presentation of a word may have more than one possible meaning and these meanings confuse the learners lexically and philologically. This is backed by the study of the reliability of meaning categorization (Twelly, Dixion, and Clark, 1994), which shows the results to be highly reliable across raters.

In the case of homographs, the associations to lexical items are linked to the related semantic characteristics, in proportion to the strength of various meanings. This was supported by findings showing that words can be used as a primer and that the amount of strength is primarily related to the features of both homographs (e.g Simpson \& Martin, Paul \& Kellas (1987), and nonhomographs (e.g Franks, Nietsch \& McCarrell, 1982; and Bavclay, 1982). Meara (1995) stated that: "presenting the different meanings of vocabulary in a list form is an efficient study method in which students can learn a large number of words in a short time" 
Homographs are transplanted to the brain and enrich the mental lexicon and raise the comprehension level. Geis and Winogard (1974) calculated test-retest reliabilities for single associations to homographs. The results showed that associations to the same meanings occurred $83 \%$ of the time. They also produced four associations to some meanings. For the first and second associations, $66 \%$ produced associations for both the meanings correctly. The results of these two studies are, however, less than decisive.

The understanding of homographs as "two words that are spelled exactly the same way, but have different meanings and sometimes different word class" normally is restricted to within one language. However, a variation of this can be seen in bilingual context as "cognates" and "interlingual homographs". Cognates overlap in two languages in spelling, semantically and often phonologically (e.g., piano refers to the same concept in both English and Spanish). Cognates usually yield easier processing than language-specific words, balanced by the cognate's target language frequency. Interlingual Homographs (IHs), on the other hand, have the same spelling but different meanings in two languages (for instance, pie refers to the English dessert but means "foot" in Arabic). Research on the meaning of bilingual lexical access focuses primarily on cross-language ambiguity In bilingual semantic processing IHs were shown to hinder the understanding, probably because two incompatible meanings of the same word have to be determined by the understanding (e.g., Dijkstra et al., 1999). Many cross-language studies have employed behavioral tasks, like the lexical decision or word naming, presented one at a time, and often in a mixed language setting. Most studies of this kind conclude that competent bilinguals show some degree of activation of both languages most of the time.

Lemhofer And Dijkstra (2004), conducted a study of "Recognizing cognates and interlingual homographs " and mentioned that many second language learners had shown confusion in catching the suitable meaning of multi-meaning words. However, the frequency of certain homographs will surely help the learners to comprehend these homographs. A study was conducted by Twilley, Dixon, Taylor, and Clark (1991) about showing the effect of homographs frequency. However, the frequency norms presently in existence for homographic meanings are unsatisfactory for many purposes. Furthermore, a number of associations are produced for each listed homograph. It is noteworthy that homographs used in this study were limited to just two meanings of each word and for different/same word classes. From this elementary beginning, it should be possible to move further and study homographs with more than two meanings.

\subsection{Theories of Lexical Semantics}

\subsubsection{Historical-philological semantics}

In the nineteenth century, linguistics took the form of historical research, and this saw the birth of historical linguistic semantics which was merely one more aspect in the development of modern linguistics. The historical and philological way is the diachronic approach to lexical semantics that dominated the discipline from the 1850s to the 1930s. Its basic interest lies in the change of meanings.

The study of meanings was more than a desire to study the linguistics change and its many aspects; rather its purpose was adequate historical investigations into the formal aspects of a language. So the first factor in the birth of linguistic semantics was the ageold tradition of word meanings, which was rejected in the wake of approaches to identify the mechanism of semantics change.

\subsubsection{The nature of meanings}

Wegener (1885) sums up the disciplinary position of historical-philological semantics. He defines semantics as linguistically valuable to the extent that it classifies the meanings in lexicography. However, it derives these laws from the nature of the mind and is a record of the history of ideas. Wegener (1885) introduced an additional aspect of historical-philological semantics; it is the approach that assumes a psychological conception of meaning, revealing the characteristics of the human mind.

\subsubsection{Cognitive semantics in the context}

According to many philologists, cognitive semantics makes significant contributions to the development of lexical semantics. First, cognitive semantics leads to innovative techniques of analyzing the internal semasiological structures of the words. Second, it shows interest in the semantics relations between semasiological structures, metonymy, and their interaction. Third, cognitive semantics has shown the importance of research on patterns of polysemy and semantic changes.

\subsubsection{Meaning in text and discourse}

Based on Fischer's studies, cognitive semantics is the most immediate type of discourse-related investigation; it is the study of discourse pragmatic makers. Grammar is not only employed in performance, but it is also the product of language uses (Langacker, 1999). Moreover, the idea is the nature of the relations between the language system and language use. Cognitive linguistics looks at meanings phenomena in different elements of discourse; it is a natural course of action.

\section{Research design and methodology \\ 3.1 Introduction}


This research revolved around the challenges of homographs and the errors made by L2 learners of the English language. Second language teachers are often inspired by the evidence of how the target language is learned from the errors made by L2 learners. Furthermore, they comment 'errors are meaningful. Errors reveal which item has been incorrectly learned by the students. This signifies that errors usually shed light on the mode in which students overlap the rules of the target language. Students, through the mistakes, might manipulate the language to achieve the meanings. Teachers must learn to recognize these problems as a sign of ingenuity and creativity.

English language teachers, must hatch a new creative strategy for their feedback. A traditional method used by teachers in correcting errors was determining the grammar mistakes only. New techniques must be implemented by the English teachers for the learners' sake. Based on some studies, it is surmised that the main cause of language errors is vocabulary deficiency. The education committee should recognize the importance of lexicon items in language acquisition. In the case of homographs misuse, the errors made by $\mathrm{L} 2$ learners provide feedback on how the meanings are interpreted within a context.

Two tests were designed to elicit a sufficient amount of data for the purpose of determining the ability of L2 learners to use homographs correctly. The author focused on two main types: that which determines the meanings, and that which categorizes word classes with associations. Twenty homographic words were chosen by the author. The vast majority of them were taken from the curriculum given to $\left(7^{\text {th }}, 8^{\text {th }}\right)$ levels of education. Each word of the list gave more than one possible meaning and different word classes. Students were required to give only two meanings for a single homograph.

30 English-language participants were allocated to each mission. Quantitative data were collected in the study. The interviewees received two types of testing. Each type was structured to gather precise data for the analysis. These tests were designed using various methods. These assessments were conceived by the head of the Department of English Languages and the College of Foreign Languages supervisors. For the review, the types of bugs were identified and tabled.

As the author found, some students could not give the first meaning and the homographs of the second meaning.

Table (1)

\begin{tabular}{|c|c|c|}
\hline Homographs & The first meaning & The second meaning \\
\hline Hide & Animal skin $(\mathrm{N})$ & To conceal (V) \\
\hline Produce & Give rise to $(v)$ & Things that have been produced or grown (n) \\
\hline Pick & A kind of tool $(\mathrm{N})$ & To choose (V) \\
\hline Fast & Quick (Adj) & To abstain from (choose not to eat) food (V) \\
\hline Train & Trails vehicle $(\mathrm{n})$ & To do exercises $(\mathrm{v})$ \\
\hline Light & Not weighting (adj) & Something affords illumination $(n)$ \\
\hline Wound & Past tense of wind $(\mathrm{V})$ & To injury (V) \\
\hline Fan & An admirer $(\mathrm{N})$ & Cooling device (V) \\
\hline Object & Topic (n) & Oppose (v) \\
\hline Minute & Tiny (adj) & Unit of time $(\mathrm{N})$ \\
\hline Pupil & Part of the eye $(\mathrm{N})$ & Student $(\mathrm{N})$ \\
\hline Tear & A liquid drop of eye $(\mathrm{N})$ & Divide by force $(\mathrm{V})$ \\
\hline Can & Able to $(v)$ & A cylindrical metal container(n) \\
\hline Bear & An animal $(n)$ & Endure (v) \\
\hline Fall & Autumn (n) & Drop down (v) \\
\hline Well & A water hole $(\mathrm{n})$ & Fine (adj) \\
\hline Dove & A kind of birds $(\mathrm{N})$ & A past tense of dive $(\mathrm{V})$ \\
\hline Ring & A small circular metal band ( $n$ ) & Resonant (adj) \\
\hline Beat & Defeat (v) & Drum, or knock (v) \\
\hline Saw & Past tense of see $(\mathrm{v})$ & Cut tool (n) \\
\hline
\end{tabular}


Data were collected for two tests that were given to the respondents. The head of the English language department and supervisors of the college of Foreign Languages gave guidance for designing these tests. Each test was designed to collect specific information for the study, using different methods. Each task was assigned to test the 30 participants of the English language. The data for the study was gathered quantitatively; the types of errors were determined and tabulated for analysis.

\subsubsection{Participants}

30 undergraduate students of Albaha University were tested. The research sample consisted of 15 males and 15 females. They all belonged to the same university and the same department. The respondents of this study were chosen randomly.

The analysis revealed that the male students showed strong superiority over the female students in the first test, while in the second test it was vice versa. The analysis of these two tests and the comparison will be explained in detail in the chapter (4).

\subsubsection{Test instrument}

An info-graphic containing homographic word clarification was given by the researcher to the learners as a contribution to avoid homographs misuse.

The author chose to construct two separate experiments on the basis of the results of related studies. After discussion with the head of the English department and other professors from the College of Arts and Humanities, the subjects of this study were decided. The researchers built the questions of the test under the authorization of the English department. The homographs were specifically designed with the purpose to obtain the following information:

a) Is the concept of homograph familiar to the learners?

b) Do students recognize the contextual meanings of these items?

\subsubsection{Test (1)}

A schedule of homographs was given to the respondents to show two different meanings for each word in the list, and to give the word class for each meaning. The purpose of giving the word class was to investigate whether the learners actually know meanings lexically and functionally, or they are giving random meanings by guessing.

The objective of this task was to determine if L2 learners knew the different meanings and word classes for each homographic word.

To illustrate more, the table below will show a part of this task in which the questions appeared:

Question (1): Show the meanings and the word classes of the following homographs:

\begin{tabular}{|l|l|l|l|l|}
\hline \multirow{2}{*}{ Homographs } & \multicolumn{2}{|l|}{ The First Meaning } & \multicolumn{2}{l|}{ The Second Meaning } \\
\cline { 2 - 5 } & The meaning & Word class & The meaning & Word class \\
\hline Light & & & \\
\hline
\end{tabular}

\subsubsection{Test (2)}

The researcher designed this task particularly to determine the ability of L2 learners to distinguish the semantic and syntactic functions of homographs within a context. In this task, 40 pairs of sentences divided into homographic and non-homographic sentences were given. Each homographic item chosen for this study was examined twice in sentence forms. 20 pairs gave the use of homographic sentences and the other 20 gave the use of non-homographic sentences.

The following table clarifies how this question was presented as a task: 
Table (2)

Question (2)- Investigate whether the following sentences give a homographic use or not, then circle the correct answer:

Example (1):

The dove flew by the garden.

Sami dove into the pool.

Example (39):

He dove into the snow while she stood.

He dove into the cold water.
(Homographic use - another)

(homographic use - Another)

L2 learners were able to distinguish the homographic sentences after they were given a situation of what a homograph was.

\section{Data analysis}

\subsection{Introduction}

This research was undertaken to investigate the incorrect and correct use of homographs among undergraduate students. The data of this study was collected using two different tests which were designed by the researcher ofor20 homographs and were given to 30 Saudi students of $\left(7^{\text {th }}-8^{\text {th }}\right)$ level. Each homograph was tested twice. On the whole, two tasks were administered to students in order to obtain data, and the data was analyzed. Further, the tests of this study were constructed in order to obtain information on the research question (Can the learners recognize the different meanings and the word classes of a homograph? In short, do they understand the contextual meaning of it?).

Tables 4 and 5 in the following pages depict the analysis of the results of each test followed by response graphs sorted by the degree of difficulty of the tests. Many of the homographic items registered similar correct and incorrect responses. Also, some of them shared the same degree of difficulty level. For instance, of the twenty homographs in test (1), homographs such as wound, dove, and fast ranked $1^{\text {st }}$ simultaneously in terms of difficulty.

\subsection{The analysis of test results}

Test (1) simply was an investigation of the comprehension of L2 students and their ability to determine two meanings for each homograph. In this test, respondents were required to mention the word class for each item. Out of 600 responses, $66 \%$ of the answers were correct for the first meaning, and 33\% were incorrect answers. On the other hand, the second meaning showed inferior results. The overwhelming majority of respondents failed to guess the second meaning, recording more than $87 \%$ of homograph misuse. Moreover, the homograph "wound" resulted in no correct responses at all in the second meaning. Consequently, among the 20 homographic items, this word proved to be the most difficult item with $0 \%$ of correct answers. This was followed by homographs such as fall, minute, and dove, which ranked the $2^{\text {nd }}$ most difficult ones. In the second meaning, the words such as wound, well, saw, minute, bear, and fast presented the most difficulty

Table (3) : 4.2.1 Percentage of correct and incorrect responses in test (1) (First Meaning)

\begin{tabular}{|l|l|l|l|l|l|l|}
\hline $\begin{array}{l}\text { No. of } \\
\text { question }\end{array}$ & Homographs & $\begin{array}{l}\text { No. } \\
\text { responses }\end{array}$ & $\begin{array}{l}\text { Correct } \\
\text { answers } \\
\text { correct } \\
\text { answers }\end{array}$ & $\begin{array}{l}\text { Percentage of } \\
\text { response }\end{array}$ & $\begin{array}{l}\text { Percentage of } \\
\text { incorrect } \\
\text { answers }\end{array}$ \\
\hline & Produce & 30 & 25 & $83 \%$ & 5 & $13 \%$ \\
\hline & Light & 30 & 25 & $83 \%$ & 5 & $13 \%$ \\
\hline & Train & 30 & 22 & $73 \%$ & 8 & $27 \%$ \\
\hline & Object & 30 & 27 & $90 \%$ & 3 & $10 \%$ \\
\hline & Fast & 30 & 10 & $33 \%$ & 20 & $67 \%$ \\
\hline & Wound & 30 & 11 & $36 \%$ & 19 & $64 \%$ \\
\hline & Pupil & 30 & 18 & $60 \%$ & 12 & $40 \%$ \\
\hline & Hide & 30 & 19 & $63 \%$ & 11 & $37 \%$ \\
\hline & Pick & 30 & 24 & $80 \%$ & 6 & $20 \%$ \\
\hline & Minute & 30 & 27 & $50 \%$ & 15 & $50 \%$ \\
\hline & Bear & 30 & 27 & $90 \%$ & 3 & $10 \%$ \\
\hline & Can & 30 & 21 & $90 \%$ & 3 & $10 \%$ \\
\hline & Fall & 30 & 20 & $66 \%$ & 9 & $30 \%$ \\
\hline & Well & 30 & & & $34 \%$ \\
\hline
\end{tabular}




\begin{tabular}{|l|l|l|l|l|l|l|}
\hline & Dove & 30 & 13 & $43 \%$ & 17 & $47 \%$ \\
\hline & Ring & 30 & 26 & $86 \%$ & 4 & $14 \%$ \\
\hline & Tear & 30 & 17 & $56 \%$ & 13 & $44 \%$ \\
\hline & Fan & 30 & 21 & $70 \%$ & 9 & $30 \%$ \\
\hline & Beat & 30 & 18 & $60 \%$ & 12 & $40 \%$ \\
\hline & Saw & 30 & 23 & $76 \%$ & 7 & $24 \%$ \\
\hline Total & 20 & 600 & 409 & $68,17 \%$ & 191 & $31,83 \%$ \\
\hline
\end{tabular}

4.2.1. Response graph of the test (1), (first meaning).

Table (4)

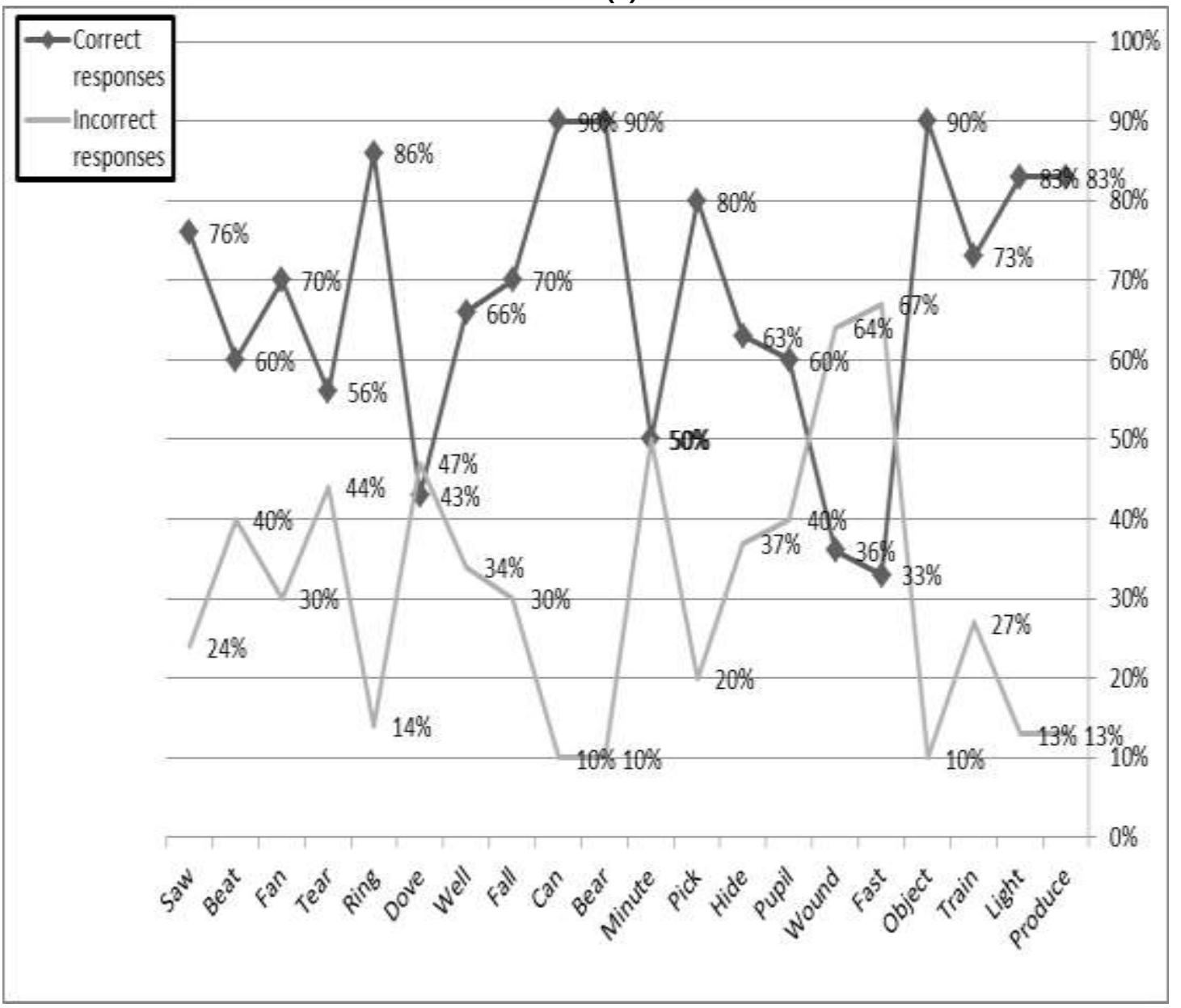

4.2.2. Response graph of the test (1), (second meaning)

Table (5) 

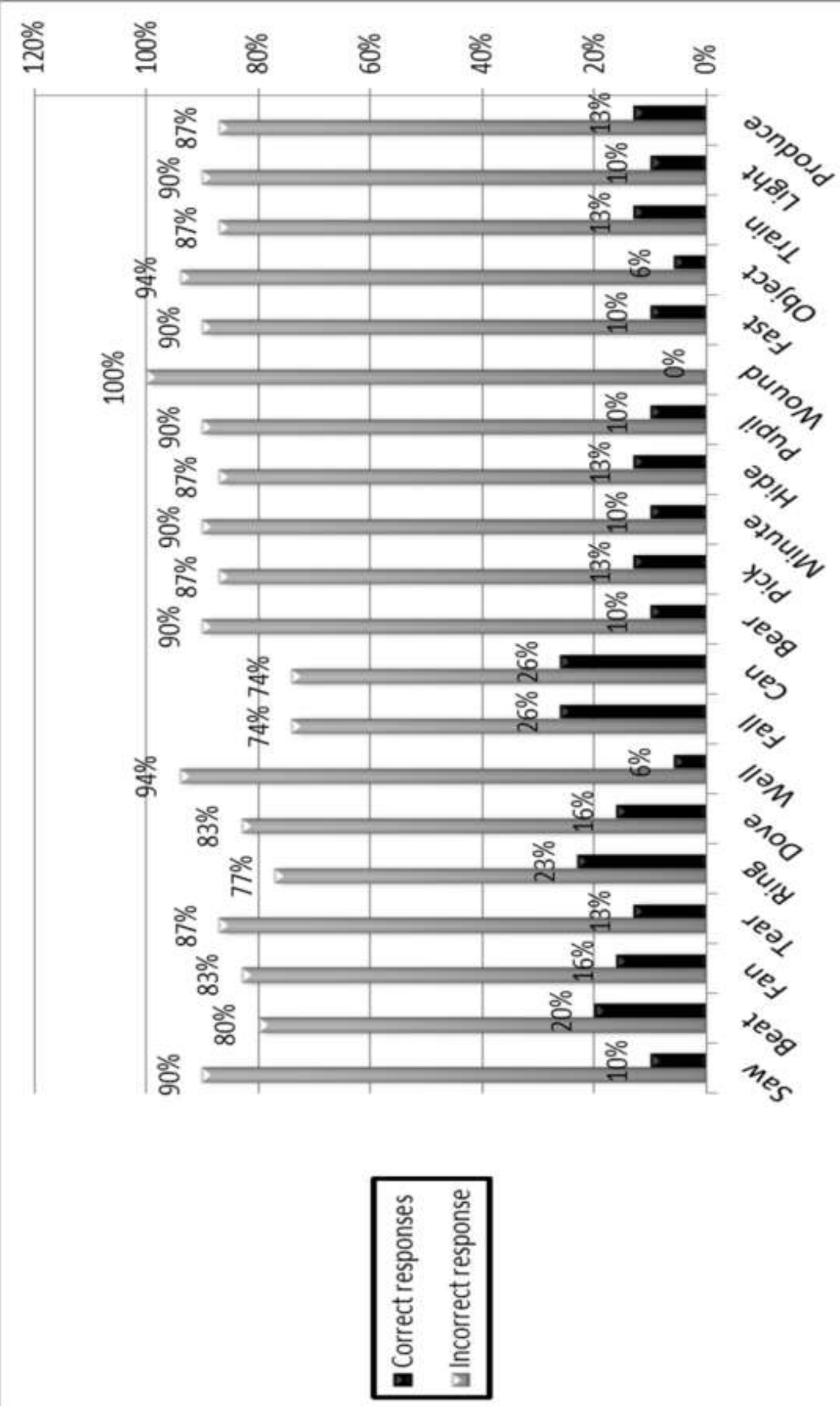


\subsection{Analysis of test (2) results}

The second test in the experiment was formed differently from the first test; it was a guided test. Here, the researcher gave the definition of homographs as a hint to recognize the homographic and non-homographic sentences. In this task, respondents were required to categorize the homographic pairs in sentences. Out of 1200 responses to identify the homographic items within context, there were $53 \%$ correct responses and $47 \%$ incorrect answers. L2 learners were able to disambiguate homographic words within contexts as seen in the experiment (2), compared to experiment (1) that asked them to give the meanings of homographs isolated without sentences.

Thus, the students could reduce the gap of homograph misuse in a given context. The percentage of correct answers in this task indicates the students' ability to comprehend homographs within a context, with better results for some items as compared to the test (1). Many students had a problem understanding the homographic item "hide", with $60 \%$ incorrect responses. This was followed by the item "minute" which accounted for only $43 \%$ correct answers, and item "wound" with $45 \%$ correct answers.

Table (6)

4.3.1. Response graph for the test (2)

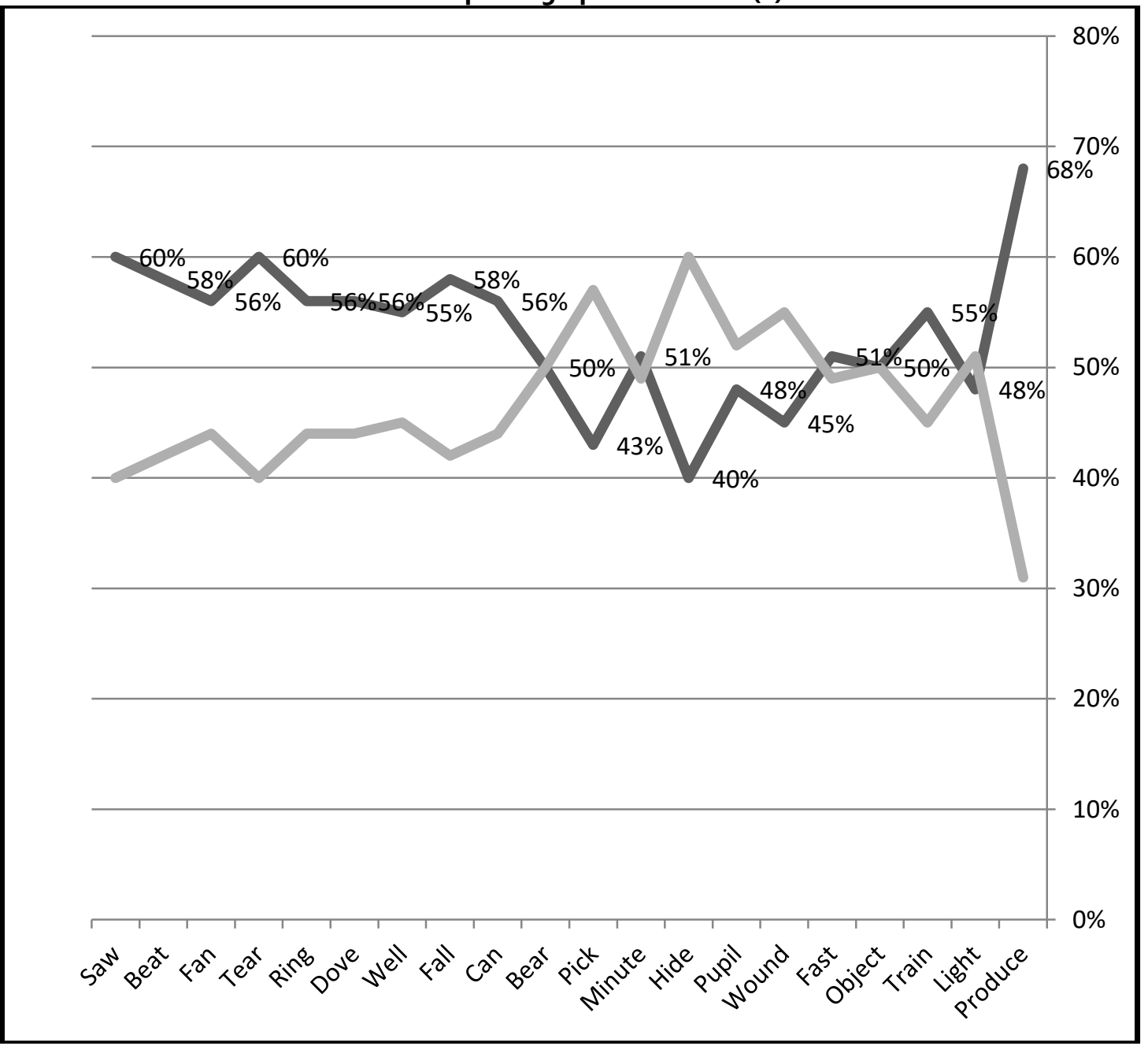

\subsection{Analysis of the use of each homograph:}

Tabulated below is the analysis of the use of each homograph in terms of correct responses for both tests. This data helped in drawing the conclusions of the study 
\% Correct responses for each homograph in each test

\begin{tabular}{|c|c|c|c|c|}
\hline Homograph & Test 1 & & Test 2 & Remarks \\
\hline & Meaning 1 & Meaning 2 & & \\
\hline Object & 90 & 6 & 50 & Best result for test 1 first meaning \\
\hline Produce & 83 & 13 & 83 & Best result for test 2 \\
\hline Light & 83 & 16 & 51 & $\begin{array}{l}\text { Third highest in test } 1 \text { along with } \\
\text { 'Produce' }\end{array}$ \\
\hline Train & 73 & 13 & 55 & \\
\hline Wound & $<37$ & 0 & 45 & $\begin{array}{l}\text { Most difficult homograph in test } 1 \\
\text { meaning } 2 \text {. This was better in Test } \\
2 \text { than } 1\end{array}$ \\
\hline Fast & 31 & 10 & 51 & Most difficult for test 1 , meaning 1 \\
\hline Dove & 43 & 16 & 56 & Third most difficult in test 1 \\
\hline Pupil & 60 & 10 & 48 & $\begin{array}{l}18 \text { correct respondents in test } 1 \text {, } \\
\text { meaning } 1\end{array}$ \\
\hline Hide & 63 & 13 & 40 & $\begin{array}{l}\text { One of the more difficult words in } \\
\text { test } 2\end{array}$ \\
\hline Pick & 80 & $\begin{array}{l}\text { (13 } \\
\text { responses) }\end{array}$ & 51 & $\begin{array}{l}24 \text { correct respondents in test } 1 \text {, } \\
\text { meaning } 1,13 \text { in meaning } 2\end{array}$ \\
\hline Minute & 50 & 10 & 43 & Fourth difficult in test 2 \\
\hline Bear & 90 & 10 & 50 & $\begin{array}{l}27 \text { correct respondents for } \\
\text { meaning } 1 \text { - good comprehension } \\
\text { Only } 2 \text { correct for meaning } 2\end{array}$ \\
\hline Can & 90 & 26 & 56 & Best response for meaning 2 \\
\hline Well & 66 & 6 & 55 & $\begin{array}{l}20 \text { correct respondents for } \\
\text { meaning } 1\end{array}$ \\
\hline Ring & 86 & 23 & 50 & Second best in Meaning 1 \\
\hline Fall & 70 & 26 & 58 & \\
\hline Tear & 56 & 13 & 60 & Students could guess well in test 2 \\
\hline Fan & 70 & 13 & 60 & $\begin{array}{l}\text { Showed progress in guessing } \\
\text { meaning in test } 2\end{array}$ \\
\hline Beat & $>60$ & 20 & 58 & \\
\hline Saw & 76 & 10 & 60 & Ranked $5^{\text {th }}$ in test 1 \\
\hline
\end{tabular}

\subsection{Types of errors}

Overall, in the responses in test (1), more than $66 \%$ of respondents could give the first meaning correctly for each homographic word. The second meaning of the test proved the lexical ambiguity of L2 learners in multi-meaning words. Only $13 \%$ correct responses for the second meaning with the word "wound" not getting any correct answers. These findings showed the deficiency of second language learners in the concept of homographs. The analysis of data collected from the test $(1-2)$ revealed the types of errors made by EFL Saudi learners in Albaha university. The errors were as follows :

a) In test (1), $87 \%$ of the participants were unable to identify the second meaning of the 20 homographic items which were especially chosen for this study. Students failed to decipher the multi-meaning for many items, showing the students' inability to comprehend lexical items syntactically and semantically. Most of the errors were in the second meaning.

b) In test (2), 53\% of respondents were able to comprehend homographs within contexts. Some respondents gave incorrect meanings for some items in test (1), but they guessed the meanings correctly in test (2) and provided more than $53 \%$ correct responses.

Thus, although these students showed more than $66 \%$ correct responses in test (1) for the first meaning, they displayed a general misuse of the second meaning of these items contained in sentences. In short, students obviously showed a lack of exposure to multi-meaning words. 


\subsection{Summary}

The findings of this study indicated many errors made by L2 learners which constituted "misuse of homographic items". These errors occurred with contextual homographs, thereby displaying the lack of comprehension of lexical items syntactically and semantically. Learners were unable to correctly use the relations and associations of many homographic words included in this study. This research shows that $L 2$ learners possess inadequate "lexical" understanding of the tested homographs. The English language learners produced many errors. Some of the attempts of respondents to give the correct meanings were hindered by their lack of linguistic resources. In short, the problem was in the lexicon deficiency of the learners.

English language teachers must realize that lexical items have a central role in language acquisition. Many students think that language in classrooms is merely lexicon, sentences, grammar, or composition which is not true. The language in classrooms is a concept that contains:

a) Identifying different lexical items and exploiting them in sentences.

b) Specifically, for L2 learners, identifying the lexical associations in sentences, as Hogaboam, T. W., \& Perfetti, C. A. (1975) pointed out.

c) Clarifying the unfamiliar lexicons in meaningful ways and creating acceptable lexical phrases.

\section{2 pedagogical implications}

In order to improve the students' sufficiency of homograph concepts, several suggestions must be taken into account. Below are a few recommendations to increase $L 2$ learners' lexical density:

- In teaching homographs, the classroom language needs to emphasize meanings and their functions. "Teachers should not merely point out the difference of meanings but also emphasize their usages in context", Hogaboam, T. W., \& Perfetti, C. A. (1975).

For example, the word "hand", is used with more than one meaning. Many students understand this word in its most used meaning, which is a part of the body. Learners are familiar with the "noun" usage more than the "verb" usage. For these kinds of multi-usage words, teachers should use some action in the middle of class, as if they start to use these kinds of words but in another meaning e.g. instead of "give me", they can say "hand me...", with the appropriate action. Here, students will start raising questions in their minds of the ambiguity in usage for this familiar word. These questions will lead the learners to investigate the various meanings of a single word. Language learning becomes more effective as learners are exposed to, and made to realize constituent vocabulary.

- English language teachers must strategize how to create interest while teaching homographs. These can include board games, quizzes, vocabulary competitions among the class groups, crossword puzzles, ...etc.) in order to make the multimeaning words easy to comprehend.

- Comparing sentences is an effective way to improve the students' language proficiency. Usually, students do not do this outside the classroom. So, English teachers must give plenty of exercises in sentences comparison for example:

* The dove flew over the garden.

* Sami dove into the pool.

- English language teachers must bear in mind that lexical learning is not merely memorization of a word. Lewis (1993) comments that to aid the acquisition of vocabulary, several classroom procedures will be helpful, such as:

a) Assisting learners in identifying lexical items correctly.

b) Encouraging their transformation from short-term to long-term memory.

c) Encouraging their recording of unfamiliar or new lexical items.

Furthermore, students in classrooms usually seek clarity for unexpected and difficult words in various texts. In most cases, teachers continue with the main topic of the lesson, ignoring clarifying and interpreting the word.

d) The English language teacher is the best source for students' learning. Moreover, teachers must be productive sources in order to enhance the learning of the students. As mentioned in the previous chapters, teachers should change their mindset, moving from the traditional manners of teaching to creative productive strategies.

e) Teachers must bring about a conducive environment for English language teaching inside and outside the classrooms. Many researchers agree that visual education assists learning more than audio education. Consequently, in the case of homographs, or any other lexical concept, teachers should associate the meaning visually as well as include them in various 
contexts, in order to expose their different usages to students. Interesting English articles should be pinned on general notice boards for students to read, Hemchua (1999).

\subsection{Conclusion}

There were several errors of English revealed in the results of this analysis, including the misuse of homographic objects by $\mathrm{L} 2$ learners. These mistakes with contextual homographs showed a lack of syntactic and semantic understanding of lexical elements. Learners misused several homographic terms included in this study in terms of relationships and connections. This investigation reveals that L2 students have insufficient knowledge of "lexical" homographs. In addition, English-speaking students make too many mistakes. Some of the respondents' frustrations in offering the right interpretation were due to their disgust that they had no language tools. Simply said, this is the issue in the lexicon of learners.

Based on some suggestions above, teachers can perhaps raise the proficiency of learners' language, especially in elements such as homographs, homonyms, homophones, and polysemous words .

Hopefully, lexical learning will be improved educationally, and the English language will be managed well as a skill. Because of the mixed study findings, more work needs to be done. Carefully managed, standardized trials with well-designed stimulus lists and well-diversified skill groups will serve better to explain matters.

Funding: Please add: "This research received no external funding" or "This research was funded by NAME OF FUNDER, grant number XXX" and "The APC was funded by XXX".

Conflicts of Interest: Declare conflicts of interest or state "The authors declare no conflict of interest."

\section{References}

[1] Geis, M. F., \& Winograd, E. (1974). Norms of semantic encoding variability for fifty homographs. Bulletin of the Psychonomic Society, 3(6), 429-431.

[2] Gorfein, D. S., Viviani, J. M., \& Leddo, J. (1982). Norms as a tool for the study of homography. Memory \& Cognition, 10(5), 503-509.

[3] Grauberg, W. (1971). An error analysis in German of first-year university students. Applications of.

[4] Hirst, G. (1992). Semantic interpretation and the resolution of ambiguity. Cambridge University Press.

[5] Hogaboam, T. W., \& Perfetti, C. A. (1975). Lexical ambiguity and sentence comprehension. Journal of verbal learning and verbal behavior, 14(3), 265-274.

[6] James, C. (1998). Errors in language learning and use: Exploring error analysis. New York: Longman.

[7] Langacker, R. W. (2008). The relevance of cognitive grammar for language pedagogy. In Cognitive approaches to pedagogical grammar (pp. 7-36). De Gruyter Mouton.

[8] Lemhöfer, K., \& Dijkstra, T. (2004). Recognizing cognates and interlingual homographs: Effects of code similarity in language-specific and generalized lexical decision. Memory \& cognition, 32(4), 533-550.

[9] Lewis, M. (1993). The lexical approach (Vol. 1, p. 993). Hove: Language teaching publications.

[10] Neill, W. T., Hilliard, D. V., \& Cooper, E. A. (1988). The detection of lexical ambiguity: Evidence for context-sensitive parallel access. Journal of Memory and Language, 27(3), 279-287.

[11] Kurcz, I. (2000). Psychologia języka i komunikacji. Wydaw. Naukowe" Scholar".

[12] Schmitt, N., \& Hemchua, S. (2006). An analysis of lexical errors in the English compositions of Thai learners. Prospect, 21 (3), 3-25.

[13] Simpson, G. B., \& Burgess, C. (1985). Activation and selection processes in the recognition of ambiguous words. Journal of Experimental Psychology: Human perception and performance, 11(1), 28.

[14] Swinney, D. A. (1979). Lexical access during sentence comprehension:(Re) consideration of context effects. Journal of verbal learning and verbal behavior, 18(6), 645-659.

[15] Twilley, L. C., Dixon, P., Taylor, D., \& Clark, K. (1994). University of Alberta norms of relative meaning frequency for 566 homog 